\title{
Review
}

\section{Rhinosporidiosis in Sri Lanka: An overview.}

Arseculeratne $\mathrm{SN}^{1 *}$

${ }^{1}$ Emeritus Professor of Microbiology, Faculty of Medicine, University of Peradeniya

\begin{abstract}
Rhinosporidiosis, an enigmatic disease, is present in 90 countries world-wide. Sri Lanka has the highest prevalence per capita, while India has the largest number of reported cases. It is now appearing in Europe. Since its discovery in 1892, unresolved enigmas of the disease and its causative pathogen, still remain. This overview highlights these enigmas to encourage Sri Lankan researchers to investigate them
\end{abstract}

Key words: Unsolved problems; Rhinosporidiosis; Rhinosporidium seeberi

Copyright: ( 2013 Arseculeratne SN. This is an open access article distributed under the Creative Commons Attribution License, which permits unrestricted use, distribution, and reproduction in any medium, provided the original work is properly cited.

*Correspondence: chubby@ sltnet.lk

How to cite: Arseculeratne SN. Rhinosporidiosis in Sri Lanka: an overview. Anuradhapura Medical Journal 2013;7(1):8-10.

DOI: http://dx.doi.org/10.4038/amj.v7i1.6135 
This review is addressed to the Anuradhapura Medical Journal in view of the facts that (1) the highest prevalence world-wide, of Rhinosporidiosis on a unitpopulation basis, is in Sri Lanka although India has had many more reported cases; (2) the Anuradhapura district has the highest national prevalence (Fig. 1); (3) many enigmas that still remain to be resolved have been identified, and it is hoped that researchers in the Anuradhapura Faculty of Medicine and Allied Health Sciences will work on them; it is indeed a gold-mine for research. It is thus a compelling onus on Sri Lankan researchers to fill the gaps in our knowledge of rhinosporidiosis.

This disease and its causative pathogen Rhinosporidium seeberi, are unique. Apart from Mycobacterium leprae that has not yet been cultured in vitro although in vitro culture has been achieved with other mycobacteria, $R$. seeberi has also not been cultured in vitro. The bacterial cell, though complex, has identifiable components that have been extensively studied and whose properties in relation to the organism's pathogenicity and the pathogenesis of the disease it causes, have been elucidated; $R$. seeberi's internal structure is also complex but as stated below, the function(s) of some of its structural components are not yet known.

Sri Lankan national data on the prevalence of this disease has been reported (1) while the disease and its causative pathogen, Rhinosporidium seeberi, were described in depth in the monograph by Arseculeratne \& Atapattu (2) .

\section{The enigmas of rhinosporidiosis}

This is a unique disease that, still, 121 years after its discovery has enigmas that remain unsolved. The unsolved features that are identifiable are:-

(1) What are the geographical features of the Anuradhapura region that make it a predominant focus of the disease?

(2) Why do Sri Lankans and Indians show a predisposition for the disease?

(3) Southern India that bears geographical similarities to Sri Lanka, has had many cases of rhinosporidiosis in a wide range of animals, although Sri Lanka has had no reported cases of rhinosporidiosis in animals of any sort.

(4) Only a minority of people exposed to R. seeberi in Nature, develop the overt disease. Are there host factors that predispose to the disease?
(5) Males, both human and anima, predominate over females as hosts; what factors are responsible for this sex difference?

(6) Is the predominance of ocular and nasal sites due to their anatomical peculiarities that promote retention of the acquired pathogen in these sites?

(7) Why is lymphatic spread rare in rhinosporidiosis, while it is common in mycotic diseases?

(8) Mechanisms of Immune Suppression has been demonstrated in $R$. seeberi. Do they play a role in the pathogenesis of rhinosporidiosis?

(10) Is there a failure of innate defence immune mechanisms in the termination of initial infection before it progresses to overt disease?

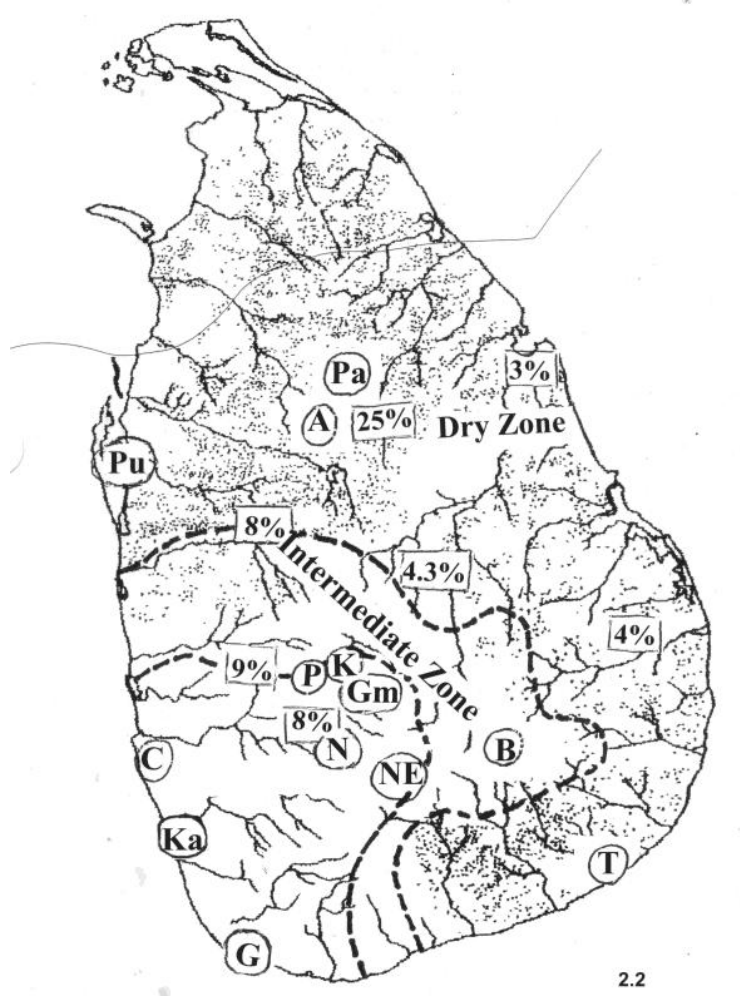

Figure 1 Map of Sri Lanka showing the percentage distribution of 143 cases of rhinosporidiosis in Sri Lanka . $\mathbf{A}=$ Anuradhapura, $\mathbf{K}=\mathbf{K a n d y}, \mathbf{P}=$ Peradeniya, $\mathbf{G m}=$ Gampola, $\mathbf{C}=$ Colombo, $\mathbf{N}=$ Nawalapitiya, $\mathrm{NE}=$ Nuwara Eliya, $\mathrm{B}=$ Bandarawela, $\mathbf{G a}=$ Galle, $\mathbf{T}=$ Tissamaharama. The dots represent small tanks containing ground-water. (from Arseculeratne et al.(2) )

\section{The enigmas of Rhinosporidium seeberi}

The causative pathogen, first characterized in 1890, is just as enigmatic as the disease it causes. 
(a) What are the properties of the natural habitat of $R$. seeberi, viz. ground waters that support its survival and growth? $R$. seeberi was detected by molecular biological in situ hybridization using $R$. specific probes, in waters from Anuradhapura reservoirs ${ }^{3}$.

(b) Genetic heterogeneity has been demonstrated 4 in strains of $R$. seeberi from different patients (Fig. 2). Are the different strains responsible for different clinical presentations of rhinosporidiosis?

(c) What the properties of the strains that determine their predilection for different sites in the host's body?

(d) Is there synergism between $R$. seeberi and other aquatic microbes in the initiation of the disease?

(e) What factors explain the inability to culture $R$. seeberi in vitro, in inanimate or animate culture media?

(f) What factors in R. seeberi or in the host could explain the inability to establish experimental rhinosporidiosis in laboratory or farm animals?

(g) What is the generation time of $R$. seeberi?

(h) What is the ultimate infective stage of $R$. seeberi? Is it the endospore, or its electron dense body?

(i) Does $R$. seeberi possess extracellular enzymes that enable the pathogen to spread locally in diseased tissues?

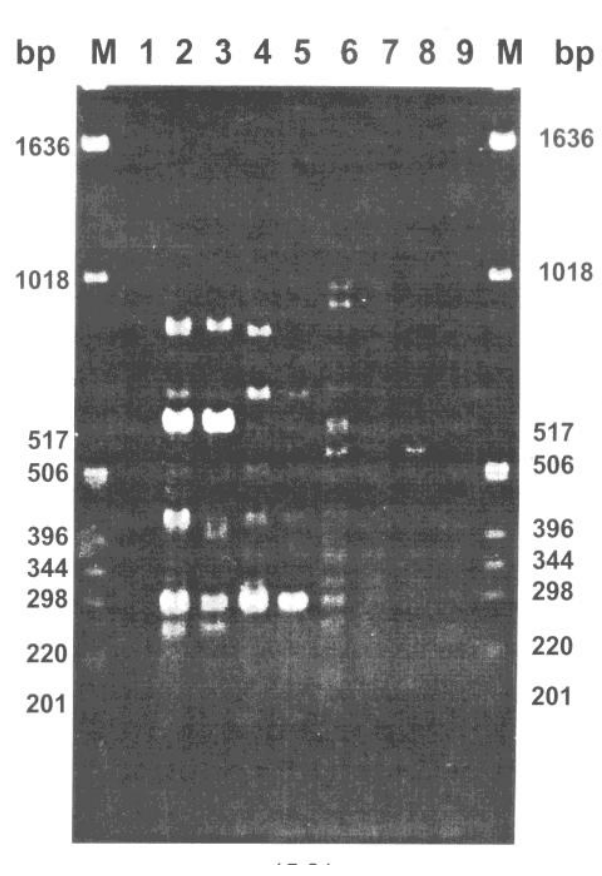

Figure 2 Analysis by Random Amplification of Polymorphic DNA (RAPD) of strain variation in $R$. seeberi in rhinosporidial tissues from 6 different Sri Lankan patients (lanes 2-7); lane 8 = human leucocyte control. Lane 9 human liver/spleen cell control. In the rhinosporidial lanes $2-7,3$ patterns are shown with 2 strains in each pattern. (From Arseculeratne et al.(2))

\section{References}

1. Arseculeratne SN, Sumathipala S, Eriyagama NB. Patterns of rhinosporidiosis in Sri Lanka: Comparison with international data. South East Asian Journal of Tropical Medicine \& Public Health 2010; 11: 175-91.

2. Arseculeratne SN, Atapattu DN. Rhinosporidiosis in Humans and Animals \& Rhinosporidium seeberi. 2011: 328-32.

3. Kaluarachchi K, Sumathipala S, Eriyagama N, Atapattu D, Arseculeratne S. The Identification of the Natural Habitat of Rhino-sporidium seeberi with R. seeberi Specific in situ Hybridization Probes. Journal of infectious diseases and antimicrobial agents 2008; 25: 25-32.

4. Appuhamy S, Atapattu DN, Arseculeratne SN, Eriyagama NB. Strain variation in Rhinosporidium seeberi. Proceedings of the Sri Lanka College of Microbiologists 2002; 25: 25-32.

\section{Submit your next Manuscript to Anuradhapura Medical Journal}

Submit your manuscript at www.sljol.info/index.php/AMJ/ 